\title{
SINCRETISMO CULTURAL NA JOALHERIA AFRO-BRASILEIRA
}

\author{
Maria Antonia Benutti ${ }^{1}$, Maria Luiza Calim de Carvalho Costa ${ }^{2}$
}

\begin{abstract}
Body adornment has been used as a ornament, ritualistic object, religious icon or as symbol demonstration of status and power in many different cultures. In Brazil, own visuality develops from the cultural syncretism. Thus, together with the mode of dress, the african-Brazilian jewelry acquires peculiarities derived from cultural identities that coexist. This paper proposes a look at africanBrazilian jewelry through visual representation in some works of Jean-Baptiste Debret - French painter member of the French Artistic Mission that registered objects and everyday scenes of slaves and freemen, of poor whites and aristocrats of Rio de Janeiro in the early nineteenth century. We are looking for jewelry as a historical record of lifestyles from a time and place with a social, economic and cultural local configuration.
\end{abstract}

Index Terms: jewel, arts, siècle XIX, Jean-Baptiste Debret.

\section{INTRODUÇÃO}

Adornos corporais têm sido usados como enfeite, objeto ritualístico, ícone religioso ou como símbolo de demonstração de status e poder nas mais diversas culturas.

No Brasil, uma visualidade própria desenvolve-se a partir do sincretismo cultural. Assim, juntamente com o modo de trajar, a joalheria afro-brasileira adquire peculiaridades derivadas de identidades culturais que coexistem.

Esse trabalho propõe um olhar para joalheria afrobrasileira através da representação visual das mesmas em algumas obras de Jean-Baptiste Debret - pintor francês integrante da Missão Artística Francesa que registrou objetos e cenas do cotidiano de escravos e homens livres, de brancos pobres e aristocratas do Rio de Janeiro no início do século XIX.

Busca-se olhar para a joalheria como registro histórico de modos de vida de uma época e lugar com suas configurações sociais, econômicas e culturais locais.

\section{JEAN-BAPTISTE DEBRET}

Jean-Baptiste Debret (1768-1848), artista neoclássico francês chegou no Brasil em 26 de março de 1816, como integrante da chamada Missão Artística Francesa, liderada por Joachim Lebreton (1760-1819) - secretário recémdestituído do Institut de France. Compunha também o grupo os pintores Nicolas Antoine Taunay, o escultores Auguste Marie Taunay, Marc e Zéphirin Ferrez, o arquiteto Grandjean de Montigny e gravador de medalhas CharlesSimon Pradier .

O contexto na França era a Restauração - com a volta da monarquia francesa dos Bourbons- momento que se torna hostil para os artistas de Napoleão. Havia interesse dos artistas acadêmicos em se retirarem da França. Por sugestão do conde da Barca, o então, príncipe Dom João (1767-1826) requer ao marquês de Marialva - representante do governo português na França - a contratação de um grupo de artistas capaz de lançar as bases de uma instituição de ensino em artes visuais na nova capital do reino - Rio de Janeiro. Aconselhado pelo naturalista Alexander von Humboldt (1769-1859), Marialva chega a Lebreton, que se encarrega de formar o grupo.

A Escola Real de Ciências, Artes e Ofícios é criada por decreto no dia 12 de agosto de 1816, estabelecendo pelo período de seis anos pensão aos artistas franceses. Contudo a escola não chega a funcionar devido à resistência de membros lusitanos do governo à presença francesa e também pelo atraso de ordem material e estrutural no qual se encontrava o Rio de Janeiro. A escola abre as portas somente dez anos após a chegada dos artistas franceses, em 5 de novembro de 1826, passando por dois outros decretos, o de 12 de outubro de 1820, que institui a Real Academia de Desenho, Pintura e Arquitetura Civil, e o derradeiro, de 25 de novembro do mesmo ano, que anuncia a criação de uma escola de ensino unicamente artístico com a denominação Academia e Escola Real.

Durante o longo tempo de espera, o francês Debret aceita encomendas oficiais como diversas telas para a família real. Por ocasião das festas comemorativas da coroação de Dom João VI, em 1818, Jean-Baptiste Debret, Auguste Taunay e Grandjean de Montigny idealizam a ornamentação da cidade. Debret também se dedica ao ensino de desenho e pintura num espaço alugado. Ao lado de suas atividades como professor e retratista da corte, Debret passou a registrar objetos e cenas do cotidiano de escravos e homens livres, de brancos pobres e aristocratas.

Após 15 anos no Brasil Debret retorna a Paris em 1831, acompanhado do discípulo Manuel José de Araújo PortoAlegre (1806-1879). Publicou em Paris, o álbum ilustrado Voyage pittoresque et historique au Brésil ou séjour d'un artiste français au Brésil, entre os anos de 1834 e 1839. Obra em três volumes cujo o primeiro aborda a vida

\footnotetext{
${ }^{1}$ Maria Antonia Benutti, Professora Doutora - Faculdade de Arquitetura Artes e Comunicação - UNESP - Universidade Estadual Paulista, Av. Luiz Edmundo Carrijo Coube, 14-01, 17043-00, Bauru, SP, Brazil, mariabenutti@ faac.unesp.br

${ }^{2}$ Maria Luiza Calim de Carvalho Costa, Professora Doutora - Faculdade de Arquitetura Artes e Comunicação - UNESP - Universidade Estadual Paulista, Av. Luiz Edmundo Carrijo Coube, 14-01, 17043-00, Bauru, SP, Brazil, marialuiza@ faac.unesp.br
} 
indígena, o segundo vida urbana carioca, onde se encontram a maior parte das pranchas dedicadas aos negros, e, no terceiro e último volume retrata 1 a história da monarquia e religiosidade católica brasileira.

O álbum de viagem pitoresca de Debret se inscreve numa tradição de organização do conhecimento sobre o mundo derivado da Ilustração. Essa ordenação, porque não dizer, enciclopédica, obedece à luz da razão (o "plano lógico" de Debret), e se baseia na articulação de narrativa escrita e linguagem visual. A credibilidade da informação contida no texto garante o dado pragmático e o conteúdo didático que se busca no testemunho do viajante, aquele que adquiriu conhecimento pela experiência. No caso do álbum pitoresco de autoria de um artista, diferentemente do álbum científico, o conjunto de ilustrações, ainda que observadas no mundo real, comporta certos "arranjos" que pretendem tornar mais prazeroso o que é dado a ver. É Ofundamental, contudo, que essa intervenção operada pelo artista não prive a ilustração do efeito de realidade, sem o que ela perderia a condição que lhe confere validade histórica. Nessa escolha do que incluir (e do que excluir) no álbum, e de como fazêlo, é que se revelam as preferências pessoais do autor [1] (PICCOLI, 2007, p.5).

O artista nos quinze anos de permanência no Brasil tornou-se um observador participante dos momentos e costumes dos nativos, dos negros e dos europeus nos trópicos. No tomo II do Voyage pittoresque et historique au Brésil constam várias imagens de mulheres negras - livres ou escravas de ganho apresentadas em primeiro plano.

As pranchas publicadas são composições de desenhos e aquarelas realizados durante a permanência do artista no Brasil. Algumas aquarelas não foram publicadas no álbum de viagem como é o caso Jovens Negras Indo À Igreja Para Serem Batizadas (Figura 1).

O sincretismo cultural e religioso é demonstrado nessa aquarela onde pode-se observar também trajes e adornos de origem europeia e africana em um arranjo ornamental peculiar e único.

As jovens negras vestem trajes e portam joias à moda crioula, as vestimentas toda branca com babados e bordadas em Richelieu e com os ombros nus. As joias volumosas, com correntões de contas em ouro com 3 e 4 voltas usados de forma a adornar também as costas, ao invés de se pendurarem na nuca. Os brincos enormes, com característica marcadamente africana, assim como a pulseira e as tornozeleiras, que nesta época eram usadas apenas por elas.

A mulher que as acompanha é, provavelmente, uma negra forra, e se veste à moda europeia, inclusive levando consigo um leque, objeto bem característico da aristocracia branca. No entanto as joias que usa seguem o mesmo estilo das negras jovens - corrente de contas de uma volta, grandes brincos e anel em ouro.
A ascensão social aparente em sua vestimenta é clara, mas, embora se vista e se calce à moda européia, todo o adorno usado por ela, joias e turbante, é de influência africana.

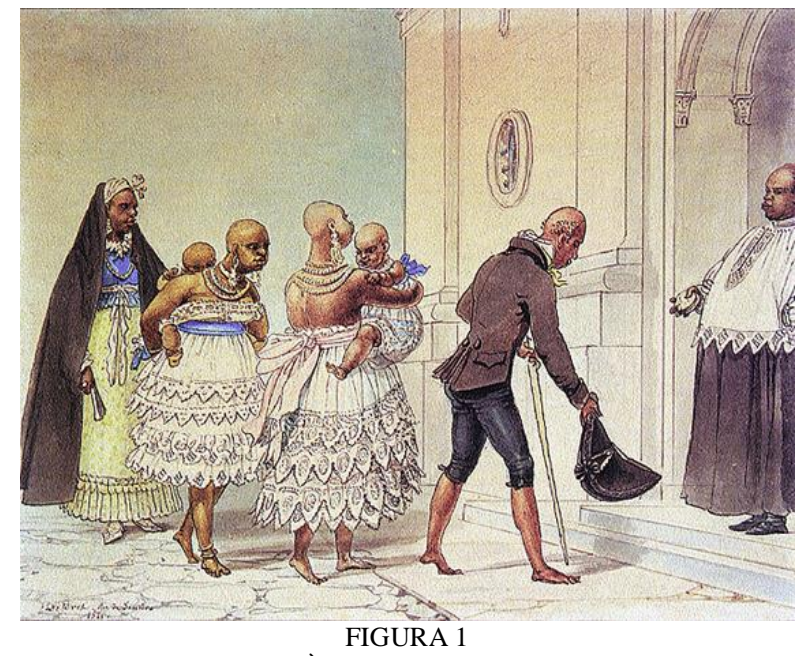

JOVENS NEGRAS INDO À IgREJA PARA SEREM BATIZADAS, 1821 JEAN-B APTISTE DEBRET, 1768-1848, AQUARELA S/ PAPEL, 18,3X23,5 CM. MUSEU CASTRO MAYA - IPHAN/MINC

REPRODUÇÃo FOTOGRÁFICA PEDRO OSWALDO CRUZ

$\mathrm{O}$ artista representa as negras aparentemente em busca do registro de costumes e da identificação das diferentes origens com vestimentas e adornos, que em muitos casos determinam o tipo de trabalho que essas negras exerciam, oriundas da cultura africana por vezes misturados com trajes e adornos de origem europeia.

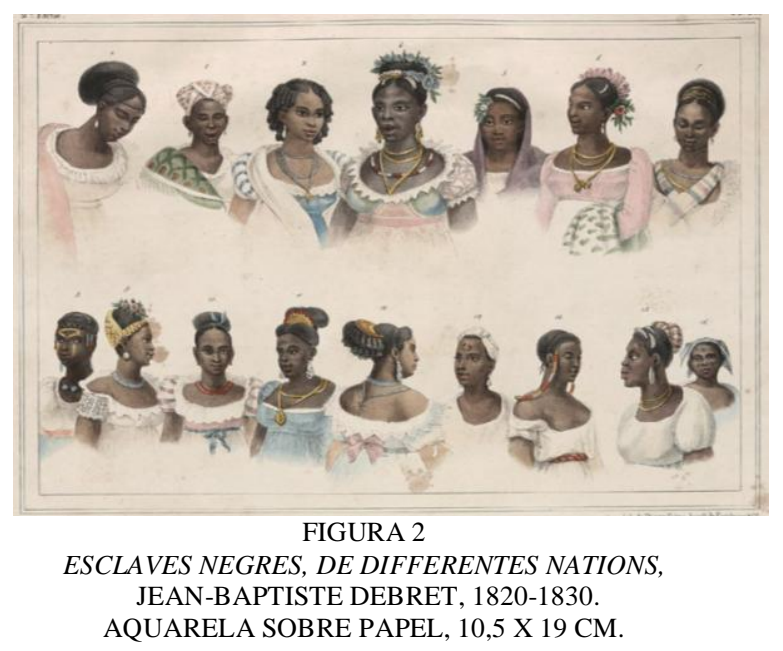

Na figura 2, Debret, como indica o título - Esclaves Negres, de Differentes Nations - retrata mulheres negras quase todas escravas oriundas de diferentes nações, evidenciadas pelas características faciais, acessórios, vestimentas, penteados e pelo texto de Debret que 
acompanha a prancha na versão litográfica (Figura 3) na publicação do álbum de viagem.

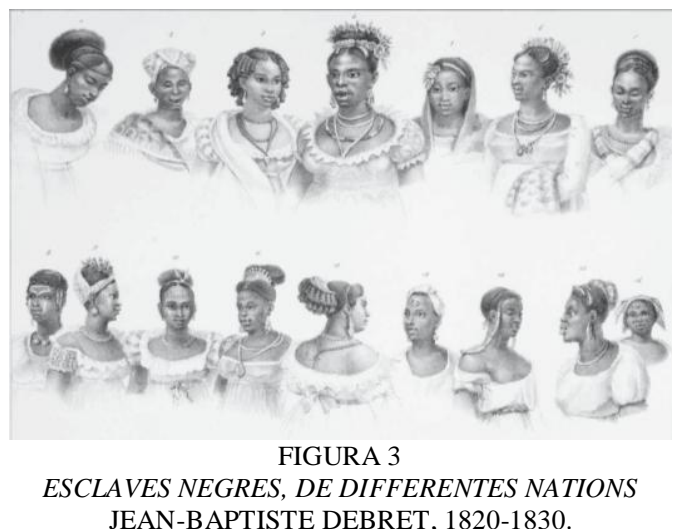

LITOGRAFIA DE THIERRY FRERES. 10,5 X 19 CM. VOYAGE PITTORESQUE ET HISTORIQUE AU BRESIL. PARIS : FIRMIN DIDOT ET FRERES, 1834-1839. TOMO II. PL. 22.

São mulheres negras oriundas de dois grandes grupos de origem africana - Bantos ou Sudaneses; e os nascidos no Brasil - Mulatos, Crioulos, Bodes - mestiço de negro com mulato. São escravas da casa ou de ganho e negras livres.

No período escravocrata, a distribuição das mulheres negras no cotidiano era extremamente complexa e nem todas tinham ou se valiam do uso de joias. Basicamente, havia as escravas da senzala, as da casa e as da rua, além das negras forras [2] CUNHA; MILZ, 2011, p.151).

O que chama atenção é que essas mulheres trazem inúmeros adornos e penteados com fivelas e enfeites, lembrando as vestimentas da sinhá. Na sociedade brasileira do século XIX, a indumentária tinha importante papel na sinalização da posição social dos indivíduos. De modo que roupas e jóias eram formas de exibição do poder econômico, social e religioso da família. As escravas urbanas, bem ornadas, indicam também a posição social de seus senhores. Assim, as escravas da casa de senhores abastados quando acompanhavam senhoras da família em suas saídas à rua, eram vestidas de seda e cobertas de joias, muitas vezes valendo bem mais que o preço de sua alforria [2] (CUNHA; MILZ, 2011).

[...] aquelas mães pretas, aquelas escravas domésticas de estimação, das quais a ética patriarcal fazia mulheres em cujos tecidos de trajos, qualidade de sapatos, apuro de adornos, o patriarca devia sentir-se obrigado a esmerar-se em adquirir artigos que proclamassem sua fidalguia. Ou sua riqueza. [3] (FREYRE, 2004, p.135)

Observa-se, então, na figura 2, as negras que possuem colares de contas, lenços, panos da Costa e penteados de matriz africana juntamente com algumas com penteados e adornos similares aos de suas sinhás.
A primeira negra, fileira de cima da esquerda para direita, Rebolo (povo proveniente de Luanda - África, pertence ao grupo dos Bantos) é adornada com um brinco perolado em forma de gota e seu penteado um grande coque adornado com tranças de cabelo que lhe cortam a testa, traja um vestido com estilo império, de algodão branco e um xale cor-de-rosa colocado como se fosse um Pano da Costa. No texto de Debret sobre a prancha: "Rebolo criada de quarto imitando com sua carapinha o penteado de sua senhora" (DEBRET, 1965, p.187).

A segunda trata-se de uma negra oriunda de Congo (África, oriunda dos Bantos). Ela traja vestido branco com um Pano da Costa estampado com motivos geométricos em verde e vermelho, na cabeça um lenço também com motivos geométricos atado como um turbante, e suas orelhas trazem brincos pequenos, bem característicos das joias de crioulas, conhecidos como "de aros". O Pano da Costa e o turbante são adornos da indumentária africana fazendo com que ela se destaque do conjunto. Texto segundo Debret: "Congo negra livre, mulher de trabalhador negro (traje de visita)" (DEBRET, 1965, p.187).

A terceira, "Cabra, crioula, filha de mulato e negra, cor mais escura que o mulato (traje de visita)" (DEBRET, 1965, p.187). Traja vestido azul com mangas bufantes listradas com estilo império, adornado com rendas brancas no decote. Sobre o vestido um xale branco. Com penteado de cachos definidos. Usa um colar de contas, provavelmente em pedras, de três voltas com pingente em forma de coração dourado, brincos parecidos com os da primeira, em pérola com formato de gota. Tanto o cabelo, as roupas e as joias são de estilo bem europeu da época.

A quarta, em destaque no centro acima, é Cabinda região de Angola, oriunda dos Bantos -, traz um grande colar em ouro com 3 voltas, que pelo caimento no colo deve ter um pingente escondido pelo decote do vestido, juntamente com o colar de contas vermelha e branca -guia do orixá Xangô-, usa grande brinco de aros dourado em formato de flor, e traz ainda adornando os cabelos uma tiara, ou pentes, em ouro decorados com pérolas e arrematados com uma coroa de flores, provavelmente uma licença poética do artista. É a que possui a vestimenta mais elaborada, com muitos detalhes e cores. $\mathrm{O}$ vestido em estilo império traz as cores branca, azul e rosa e enfeites com renda e bordados. O texto de Debret: "Cabinda, criada de quarto, vestida para levar uma criança a pia batismal." (DEBRET, 1965, p.187).

A quinta, Crioula - filha de africanos, nascida no Brasil, traz como adorno uma grande flor de tecido presa à tiara. Embora a descrição de Debret seja "Crioula, escrava de casa rica, de baeta na cabeça" (DEBRET, 1965, p.187), é uma das com a vestimenta mais simples e quem usa menos adornos, sendo estes, além da flor de tecido, um pequeno brinco e a tiara.

A sexta, "Cabina, criada de quarto de uma jovem senhora rica" (DEBRET, 1965, p.187), leva um coque enfeitado com flores e com um pente de marfim, ou de osso, usa um cordão em ouro de três voltas com 3 pingentes, que

\section{(C) 2014 WCCA}

VII World Congress on Communication and Arts

April 20 - 23, 2014, Vila Real, PORTUGAL 
podem ser amuletos de proteção e um brinco em forma de gota. $\mathrm{O}$ vestido com estilo império é branco e rosa com o decote enfeitado de renda. Carrega nos braços um Pano da Costa estampado.

A sétima, Benguela, "Criada de quarto de uma casa opulenta" (DEBRET, 1965, p.187). Com coque envolto por uma larga tiara, usa brincos com gema, colares de contas e um grosso cordão em ouro. $\mathrm{O}$ vestido branco, arrematado no decote com rendas e com Pano de Costa listado, mas colocado de forma diferente, cruzado no peito.

A oitava, "Calava jovem escrava vendedora de legumes, tatuada com terra amarela; penteada com uma tira de crina bordada, com contas e pingentes do mesmo tipo no cabelo" (DEBRET, 1965, p.187). Usa brincos em forma de pingentes e colar com grandes contas azuis. A roupa é uma saia azul, camisa branca e faixa vermelha na cintura.

A nona, "Moçambique, negra livre recém-casada." (DEBRET, 1965, p.187). Está de perfil com cabelo preso por um tecido amarelo e adornado com rosa, o colar de contas azuis dá duas voltas próximas do pescoço e o brinco em forma de pitanga, bem característico das joias de crioulas, parece ser de prata ou de gema com cor clara. $\mathrm{O}$ vestido em estilo império, de tecido branco tem as mangas bordadas e é enfeitado com rendas.

A décima "Mina, primeira escrava de um negociante europeu (favorita sujeita a chicotadas)" (DEBRET, 1965, p.187) Tem o cabelo preso em coque, arrematado por uma fina fita azul. Traz no pescoço um colar de contas vermelhas, e pequenos brincos de conta escura. Seu vestido rosa com mangas bufantes enfeitado na cintura por um laço azul é também no estilo império.

A décima primeira "Monjola, antiga ama e pajem de casa rica." (DEBRET, 1965, p.187). Traja um vestido azul com penteado em coque com uma coroa dourada, os brincos são longos provavelmente em prata com pedrarias, usa um longo cordão dourado em duas voltas afastadas do pescoço com um grande pingente em forma de camafeu.

Décima segunda, "Mulata, filha de branco com negra, concubina "tenda e mantenda". (DEBRET, 1965, p. 187). Está ao centro abaixo, com vestido branco e laço rosa na cintura, representada de costas o que possibilita ver o cabelo todo trabalhado em cachos, arrematado com uma grande tiara, e o detalhe do colar com o pingente em forma de laço nas costas. O outro colar é de contas, curto com duas voltas no pescoço e os brincos bem grandes e prateados.

Décima terceira, "Moçambique, escrava em casa de gente abastada" (DEBRET, 1965, p. 187). Usa um bioco, que é uma mantilha de algodão usada pelas mulheres para cobrir os cabelos. Traja uma roupa bastante simples e como adorno apenas um brinco de material branco.

A décima quarta, "Banguela, escrava vendedora de frutas, penteada com vidrilhos".(DEBRET, 1965, p. 187). Traja vestido de algodão branco, modelo simplório tipo camisolão com faixa de tecido amarela e vermelha na cintura. Seu ornamento preso ao cabelo nas têmporas é um longo cordão de vidrilhos que ficam em evidência.
A décima quinta, "Cassange, primeira escrava de um artífice branco" (DEBRET, 1965, p. 187). Representada de perfil, seu coque está todo coberto por um tecido listrado de branco e vermelho e 3 pentes de prata enfeitam a cabeça. traz colar curto de duas voltas em ouro e é a única com brincos de argolas em um material branco que pode ser osso ou marfim. Está com um vestido todo branco com mangas bufantes bem simples.

"Angola' negra livre quitandeira" (DEBRET, 1965, p. 187). Traz à mostra, apenas, um lenço estampado em azul na cabeça. É interessante notar que todas, com exceção dela usam brincos e segundo Godoy (2006, p.71) "os brincos tinham no seu uso um significado simbólico de proteger a cabeça através dos orifícios mais expostos aos espíritos malignos".

Embora Debret apresente mulheres de grupos variados, alguns elementos são recorrentes: como o uso de brincos, os cabelos presos, os longos colares usados com duas ou mais voltas, e um detalhe de adorno, ainda não citado, que são as tatuagens no rosto de várias delas e finalmente, os vestido em estilo império, aparentemente como traje de passeio das negras da casa ou das negras forras, traje usado também pelas sinhás.

\section{CONSIDERAÇÕES FINAIS}

A obra ESCLAVES NEGRES, DE DIFFERENTES NATIONS de Jean-Baptiste Debret é um conjunto de bustos de mulheres negras composto como um mostruário para satisfazer a curiosidade dos europeus da primeira metade século XIX. Embora apresentadas em conjunto, o leitor tende a ver cada uma das dezesseis mulheres como um retrato isolado, devido aos detalhamentos das imagens.

A descrição visual que Debret faz das mulheres negras evidenciam o sincretismo existente na cultura brasileira no Rio de Janeiro do século XIX. Negras com colares de contas, panos da Costa e pentados da matriz africana aparecem misturados com trajes, adornos e joalheria de origem européia, tais peculiaridades derivam de identidades culturais que coexistem e se amalgamam.

\section{REFERÊNCIAS}

[1] DEBRET, Jean-Baptiste. Viagem pitoresca ao Brasil. Tradução Sérgio Milliet.4a edição. São Paulo: Livraria Martins Editora, 1965.

[2] CUNHA, Laura; MILZ, Thomas. Joias de Crioula. São Paulo: Terceiro Nome, 2011.

[3] FREYRE, Gilberto. Casa Grande e Senzala: formação da família brasileira sob o regime da economia patriarcal. São Paulo: Global, 2004.

[4] PICCOLI, Valéria. O Brasil na Viagem Pitoresca e Histórica de Debret. 19\&20, Rio de Janeiro, v. II, n. 1, jan. 2007. Disponível em: <http://www.dezenovevinte.net/obras/obras_debret_vp.htm>.

[5] GODOY, Solange. Círculo das Contas: joias de crioulas baianas. Salvador: Fundação Museu Carlos Costa Pinto, 2006. 108 p.

\section{(C) 2014 WCCA}

April 20 - 23, 2014, Vila Real, PORTUGAL VII World Congress on Communication and Arts 